\title{
Differences in yield determining processes of groundnut (Arachis hypogaea L.) genotypes in varied drought environments ${ }^{1}$
}

\author{
By D. C. GREENBERG*, J. H. WILLIAMS and B. J. NDUNGURU \\ ICRISAT Sahelian Center, B. P. 12404 Niamey, Niger (via Paris) \\ (Accepted 18 March 1992)
}

\begin{abstract}
Summary
Thirty-six groundnut gentoypes of varied origin were evaluated for their yield, crop growth rates $(C)$, and partitioning to reproductive sinks $(p)$ in three trials. In the trials irrigation and sowing date were used to vary the amount of water available either throughout the crops' life, or through the grain filling phase. Genotype performance across the five environments for these attributes showed that although differences in $\mathrm{C}$ existed, differences in the stability of the partitioning were the dominant attribute of genotypes adapted to the drought prone Sahelian region. Data suggested that these differences were more attributable to tolerance to temperature and/or humidity than water stress. Over all treatments canopy temperatures relative to air (CATD) were strongly correlated with the $\mathrm{C}$ observed, but not so with yield; and differences between genotypes in the relationship between $\mathrm{C}$ and CATD were not statistically significant.
\end{abstract}

Key words: Arachis hypogaea, groundnut, genotypes, yield determination, crop growth rate, partitioning, drought tolerance

\section{Introduction}

Drought is a common problem facing dry-land farmers of the semi-arid tropics (SAT) and the development of genotypes that are more productive in these conditions has been an objective of many breeding programmes for crops exposed to this production problem. Groundnuts have also been the subject of research and development to increase drought tolerances (e.g. Gautreau \& de Pins, 1980). Agroclimatologically, droughts are complex situations and the plants/crops may experience various combinations of water deficit, high temperature, and nutrient unavailability as a result of inadequate water supply. These factors, above or below critical values, are independently damaging to the reproductive physiology of the crop (Fortainer, 1957; de Beer, 1963; Rajendrudu \& Williams, 1987; Harris, Matthews, Nageswara Rao \& Williams, 1988). Climatic droughts are also commonly associated with below normal atmospheric humidity, a factor which can, in its own right, reduce the proportion of flowers producing pods in groundnuts (Lee, Ketring \& Powell, 1972).

Breeding of crops to improve their tolerance to drought has attracted considerable research effort, and much has been written about the mechanisms that contribute to the 
differences between drought susceptible and drought tolerant types (e.g. Blum \& Sullivan, 1986), and about viable methods of identifying genotypes (e.g. Blum \& Ebercon, 1982; Chaudhuri et al., 1986) with the desired attributes both for use as parents in crossing programmes, and for selection in segregating populations. To assist breeders to select for genotypes with stability of attributes over a range of environments, the method proposed by Finlay $\&$ Wilkinson (1963) has gained widespread acceptance.

For indeterminate crops Duncan, McCloud, McGraw \& Boote (1978) proposed that yield differences could be anlysed against the model:

$\mathrm{Y}=\mathrm{C}^{*} \mathrm{~d}^{*} \mathrm{P}$

where $\mathrm{Y}$ is yield, $\mathrm{C}$ is the mean crop growth rate, $\mathrm{d}$ is the duration of reproductive growth, and $p$ is the mean fraction of crop growth partitioned towards the reproductive sinks.

The duration of a crop is known to be a primary determinant of the adaptation of genotypes to a given environment; and to be very significant in allowing varieties to escape end-season droughts. Duration differences between genotypes can, however, confound evaluation of varieties for other environments if only yields are taken into account. To date there have been a number of analyses of the yields of various crops exploiting the Duncan et al. (1978) model (e.g. Flohr, Williams \& Lenz; 1990), but these have been restricted to a small number of treatments because of the need to undertake growth analysis to determine the $\mathrm{C}$ and $\mathrm{p}$ parameters. These limitations have prevented the use of this process based approach to selection of genotypes because of the conflicting needs to have detailed growth analysis and the need to handle large numbers of genotypes.

Recently, J. H. Williams \& Ramraj (unpublished) have shown that final yield data combined with phenological observations can provide good estimates of the $C$, and $p$, determinants of yield without the need for destructive growth analysis. This paper reports the evaluation of 36 groundnut genotypes for their yield determining ( $C$ and $p$ ) attributes in five different environments with varied water supply and physical environments.

\section{Materials and Methods}

Three trials were grown at the ICRISAT Sahelian Center, Niamey, Niger, in 1989. The first was planted on 2 February in the dry season. This trial was a split-plot design with three irrigation treatments replicated three times as the main plots. The quantity of irrigation applied on any day was calculated by estimating, according to the Penman equation (using historic data) the potential daily evapotranspiration on the date of irrigation and multiplying this amount by 5 . In the three irrigation treatments (respectively, $E_{1}, E_{2}$ and $E_{3}$ ) the calculated quantity.was applied once every 5,10 or 15 days, giving these treatments $100 \%$, $50 \%$ and $33 \%$ of the cumulative potential evaporation (Table 1). All treatments were given sufficient irrigation to establish the crop and the different irrigation treatments were imposed three weeks after sowing. Each main plot was surrounded by $1.5 \mathrm{~m}$ of borders on all sides. and contained two replicates of sub-plots of 36 groundnut genotypes arranged in a $6 \times 6$ simple lattice design. The sub-plots were each three rows of $1.5 \mathrm{~m}$ length with $0.5 \mathrm{~m}$ between rows. To avoid the stress treatments receiving more water as a consequence of remaining in the field for a longer period, all three irrigation treatments were harvested when the $E_{1}$ treatment, for each groundnut genotype, was mature.

Once flowering had commenced the difference between canopy temperature and air temperature $\left(\mathrm{CATD}^{\circ} \mathrm{C}\right.$ ) was observed twice each week for $8 \mathrm{wk}$ on all plots. Observations were made between 1300 and $1400 \mathrm{~h}$.

The second and third trials were planted on 31 July 1989, about once month after the rains had established. One trial was irrigated through to maturity after the rains finished 
Table 1. Environmental details, mean crop growth rates, partitioning, duration and yields for selected genotypes

$\begin{array}{lcccccc}\text { Trial Environments } & \text { E1 } & \text { E2 } & \text { E3 } & \text { E4 } & \text { E5 } & \text { Mean } \\ \text { Mean Max T }{ }^{\circ} \mathrm{C} & 38.9 & 38.7 & 38.7 & 34.1 & 34.1 & \\ \text { Mean Min T }{ }^{\circ} \mathrm{C} & 22.9 & 22.9 & 22.9 & 22.4 & 22.4 & \\ \text { Mean Relative Humidity 1400h } & 15.2 & 15.9 & 15.9 & 50.0 & 50.0 & \\ \text { Pan Evaporation mm (Total) } & 1188 & 1188 & 1188 & 483 & 543 & \\ \text { Rain and/or Irrigation mm } & 1200 & 600 & 400 & 520 & 460 & \\ \text { Radiation Mj } \mathrm{m}^{-2} \mathrm{~d}^{-1} & 19.6 & 19.5 & 19.5 & 17.4 & 17.4 & \\ \text { Thermal time to maturity }{ }^{\circ} \mathrm{C} \mathrm{d} & 2265 & 2272 & 2271 & 2087 & 2069 & 2193 \\ \text { Total Biomass t ha-1 } & 4.64 & 3.13 & 2.11 & 3.14 & 2.44 & 2.86 \\ \text { Crop Growth Rate } \mathrm{kg} \mathrm{ha}^{-1}{ }^{\circ} \mathrm{C} \mathrm{d}^{-1} & 2.33 & 1.36 & 0.92 & 1.44 & 1.13 & 1.43 \\ \text { Pod Growth Rate } \mathrm{kg} \mathrm{ha}^{-1}{ }^{\circ} \mathrm{C} \mathrm{d}^{-1} & 1.24 & 0.50 & 0.22 & 1.31 & 1.03 & 0.86 \\ \text { Partition Coefficient } & 0.52 & 0.36 & 0.24 & 0.91 & 0.90 & 0.58 \\ \text { Pod yield t ha-1 (mean 35 cvs) } & 0.78 & 0.51 & 0.23 & 1.11 & 0.84 & 0.69 \\ \text { Pod yield (t ha-1) of } & & & & & & \\ \text { example varieties } & & & & & & \\ \text { 55-437 } & & & & & & \\ \text { ICGV 87123 } & 0.83 & 0.61 & 0.26 & 0.99 & 0.86 & \\ \text { 796 } & 0.97 & 0.58 & 0.29 & 1.34 & 0.82 & \\ \text { 28-206 } & 0.94 & 0.61 & 0.38 & 1.15 & 0.84 & \\ \text { ICGV-SM 85045 } & 0.72 & 0.39 & 0.16 & 1.15 & 0.66 & \\ \text { S.E. ( } \pm \text { ) } & 0.88 & 0.51 & 0.32 & 1.25 & 0.88 & \end{array}$

on 5 October (considered to be the control environment; $E_{4}$ ), and the second was subjected to end-season drought (environment $E_{5}$ ). The irrigated trial was given irrigation for between 20 and 34 days, according to the duration of different genotypes. Each trial contained 36 groundnut genotypes (one genotype from trial 1 could not be used due to poor seed viability, so 35 were common to all trials), arranged as a $6 \times 6$ lattice with four replicates with fiverow plots $3 \mathrm{~m}$ long with rows $0.5 \mathrm{~m}$ apart $\left(7.5 \mathrm{~m}^{2}\right.$ plot area). The trials were harvested between 25 October and 11 November, the harvest dates being determined by the maturation of varieties.

In all trials plots were regularly observed to determine the date at which $50 \%$ of the plants had commenced flowering. At harvest the dry weights of haulms, pods and kernels were determined. The first trial took a much longer calendar time to reach maturity than the second and third trials, due to low temperatures in February and March. Because of this, the times between sowing, flowering and maturity were converted to thermal time $\left(\mathrm{C}^{\circ} \mathrm{d}\right)$ using daily temperature (data recorded at the ISC meteorological station) and the equations below (Mohamed, Clark \& Ong, 1988), which assumes a base temperature $\left(T_{b}\right)$ for development of $10^{\circ} \mathrm{C}$; an optimum $\left(\mathrm{T}_{0}\right)$ of $30^{\circ} \mathrm{C}$ and a maximum $\left(\mathrm{T}_{\mathrm{m}}\right)$ of $40^{\circ} \mathrm{C}$ (Fortanier, 1957).

$T T\left(C^{\circ} d\right)=\left(T_{\max }+T_{\min }\right) / 2-T_{b}$

or if $T_{\max }$ exceeded $T_{0}$

$T T\left(C^{\circ} d\right)=\left(T_{m}-\left(T_{\max }+T_{\min }\right) / 2\right) *\left(T_{0}-T_{b}\right) /\left(T_{m}-T_{0}\right)$

Crop growth rates (C) were calculated as the linear rate of increase in $\mathrm{t} \mathrm{ha}^{-1} \mathrm{C}^{\circ} \mathrm{d}^{-1}$ over the total crop growth period after adjusting for the high energy content of the seeds (Duncan et al., 1978); as was the pod growth rate (P) for the time between $50 \%$ flowering and 
maturity of each genotype. The partition coefficient $(\mathrm{p})$ was calculated as $(\mathrm{P} / \mathrm{C})$. This approach to analysis allowed adjustments to be made for differences in time to maturity between trials and genotypes.

To compare the performance of varieties across the different environments the data for $C$ and $\mathrm{p}$ from each irrigation treatment in all trials was considered as an environment for a genotype stability analysis (Finlay \& Wilkinson, 1963). Normally, stability analysis depends on the linear regression of an individual variety's data against the mean of all varieties for each environment; however, in the case of partitioning a number of lines demonstrated statistically curvilinear relationships and where appropriate these higher order regressions have been presented.

The CATD data was averaged over all observation dates and the relationship between CATD and C investigated by regression for each genotype.

Table 2. Stability of crop growth rate across environments for 35 groundnut genotypes at ICRISAT Sahelian Center

\begin{tabular}{lrcccc} 
& \multicolumn{5}{c}{ Stability parameters } \\
Genotype & 'a' term & s.E.( \pm ') & 'b term & s.E.( \pm$)$ & $\mathbf{r}^{2}$ \\
ICGV 87259 & 0.089 & 0.283 & 0.968 & 0.263 & 0.819 \\
ICGV 87260 & -0.259 & 0.130 & 1.059 & 0.121 & 0.962 \\
ICGV 87255 & 0.265 & 0.121 & 0.736 & 0.112 & 0.935 \\
ICGV 86206 & -0.285 & 0.163 & 1.156 & 0.151 & 0.951 \\
ICGV 86599 & -0.374 & 0.303 & 0.924 & 0.281 & 0.782 \\
ICGV 86621 & -0.142 & 0.093 & 1.090 & 0.087 & 0.981 \\
ICGV 86630 & -0.026 & 0.159 & 0.983 & 0.148 & 0.936 \\
ICGV 86644 & 0.515 & 0.182 & 0.490 & 0.169 & 0.737 \\
ICGV 86647 & -0.151 & 0.066 & 0.992 & 0.061 & 0.989 \\
ICGV 86055 & -0.007 & 0.174 & 1.140 & 0.161 & 0.943 \\
ICGV 86056 & 0.415 & 0.175 & 0.771 & 0.163 & 0.882 \\
ICGV 86061 & 0.169 & 0.190 & 1.079 & 0.177 & 0.925 \\
ICGV 86015 & 0.166 & 0.228 & 0.966 & 0.212 & 0.874 \\
ICGV 87354 & 0.283 & 0.103 & 0.845 & 0.096 & 0.963 \\
ICGV 86352 & -0.148 & 0.283 & 1.035 & 0.263 & 0.837 \\
55-437 & 0.165 & 0.031 & 0.798 & 0.029 & 0.996 \\
TS 32-1 & -0.105 & 0.038 & 1.187 & 0.035 & 0.997 \\
ICGV 86973 & -0.220 & 0.133 & 1.099 & 0.123 & 0.964 \\
ICGV 86977 & -0.049 & 0.213 & 0.824 & 0.198 & 0.852 \\
ICGV-SM 85005 & -0.116 & 0.231 & 1.055 & 0.215 & 0.889 \\
ICGV-SM 83708 & -0.395 & 0.439 & 1.418 & 0.408 & 0.801 \\
ICGV-SM 85038 & -0.313 & 0.499 & 1.119 & 0.463 & 0.660 \\
ICGV-SM 85045 & 0.246 & 0.088 & 0.921 & 0.082 & 0.977 \\
ICGV 86047 & 0.095 & 0.157 & 1.011 & 0.145 & 0.942 \\
ICGV 86063 & -0.150 & 0.115 & 1.136 & 0.107 & 0.974 \\
ICGV 86072 & 0.060 & 0.078 & 0.976 & 0.072 & 0.984 \\
ICGV 87123 & 0.070 & 0.193 & 1.009 & 0.180 & 0.913 \\
ICGV 87141 & -0.309 & 0.131 & 1.302 & 0.121 & 0.975 \\
ICGV 86028 & 0.186 & 0.148 & 0.764 & 0.138 & 0.911 \\
ICG 1697 & -0.091 & 0.186 & 0.964 & 0.173 & 0.912 \\
796 & 0.011 & 0.138 & 0.913 & 0.128 & 0.944 \\
J 11 & 0.389 & 0.182 & 0.813 & 0.169 & 0.886 \\
JL 24 & 0.237 & 0.149 & 0.954 & 0.139 & 0.940 \\
28-206 & -0.353 & 0.336 & 1.490 & 0.313 & 0.883 \\
WB-9 & -0.385 & 0.088 & 1.364 & 0.082 & 0.989 \\
& & & & &
\end{tabular}




\section{Environments}

\section{Results}

The mean temperatures, relative humidities, water (irrigation and/or rain), and radiation levels during the trials are detailed in Table 1. The thermal time for the crops to mature in the trials were very similar for most genotypes; the largest difference between trials for any genotype was $15 \%$, but the difference between trials averaged over all genotypes was smaller.

\section{Yields and biomass}

The pod yields of six contrasting genotypes in these environments, mean biomass and seed yields in these trials are shown in Table 1. Significant differences in yield were found between genotypes within trials. The pod yields were greatest in the rainy season $\left(E_{4}\right)$, but by far the greatest haulm yields were achieved in $E_{1}$. The data for the one variety which was not utilised in all trials was not used in the stability analyses.

\section{Crop growth rate}

Differences in $\mathrm{C}$ between irrigation environments were substantial; while the variation between genotypes within environments was generally smaller. When $C$ of each variety was regressed on the environmental means (Finlay \& Wilkinson, 1963) the response of individual genotypes (Table 2) was usually strongly linear, as is reflected in the generally high $R^{2}$ in the stability analysis. However, the " $a$ " term was inversely related to " $b$ " $(Y=1-0.857 x$;

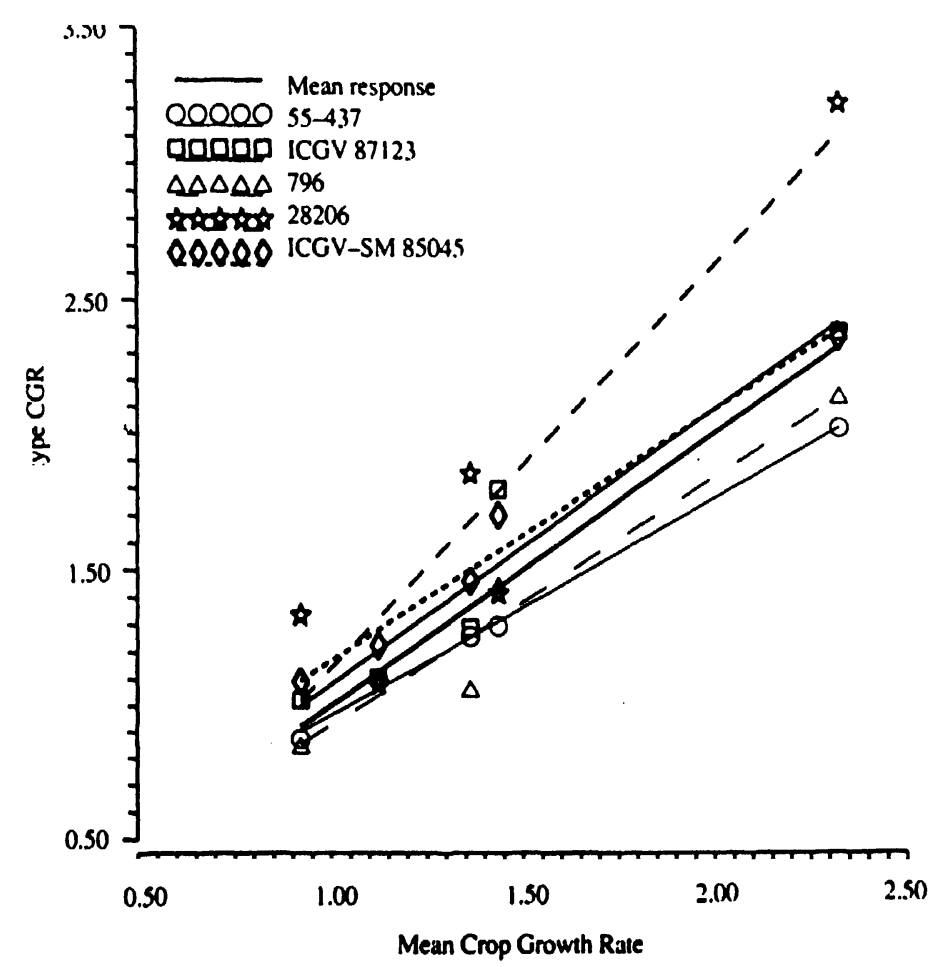

Fig. 1. Crop growth rate $\left(\mathrm{kg} \mathrm{ha}^{-1}{ }^{\circ} \mathrm{Cd}\right)$ of example varieties relative to the mean of 35 genotypes in five environments. 
$\mathrm{R}^{2}=0.81$ ), showing that the genotypes whose $C$ had large increases with increasing water supply were those with the lowest $C$ values under severe drought. The regression of genotype crop growth rate on environment mean growth rates, for example genotypes differing in drought response, are presented in Fig. 1.

The CATD (in Trial 1) across all the genotypes and environment was strongly correlated with the $C\left(R^{2}=0.88\right)$. Although there were no statistically significant differences between individual genotypes in the relationships of $C$ with CATD across the irrigation environments the long season genotypes tended to have higher growth rates and cooler leaves (indicative of better water capture) than early maturing genotypes (Fig. 2).

\section{Partitioning}

In trial 1 the mean partitioning showed a steady decline as the environments became less favourable (greater irrigation intervals), but in the second and third trials partitioning coefficients were, generally speaking, high (c. 0.90$)$ (Table 1). Stability of partitioning of genotypes across these environments demonstrated considerable variation (Table 3 ), and the responses differed from those observed for $\mathrm{C}$ in that some very strongly curvilinear patterns were observed (Fig. 3), with negative values of the second order component of the regression (b2) indicating above average partitioning under intermediate drought conditions.

4.07

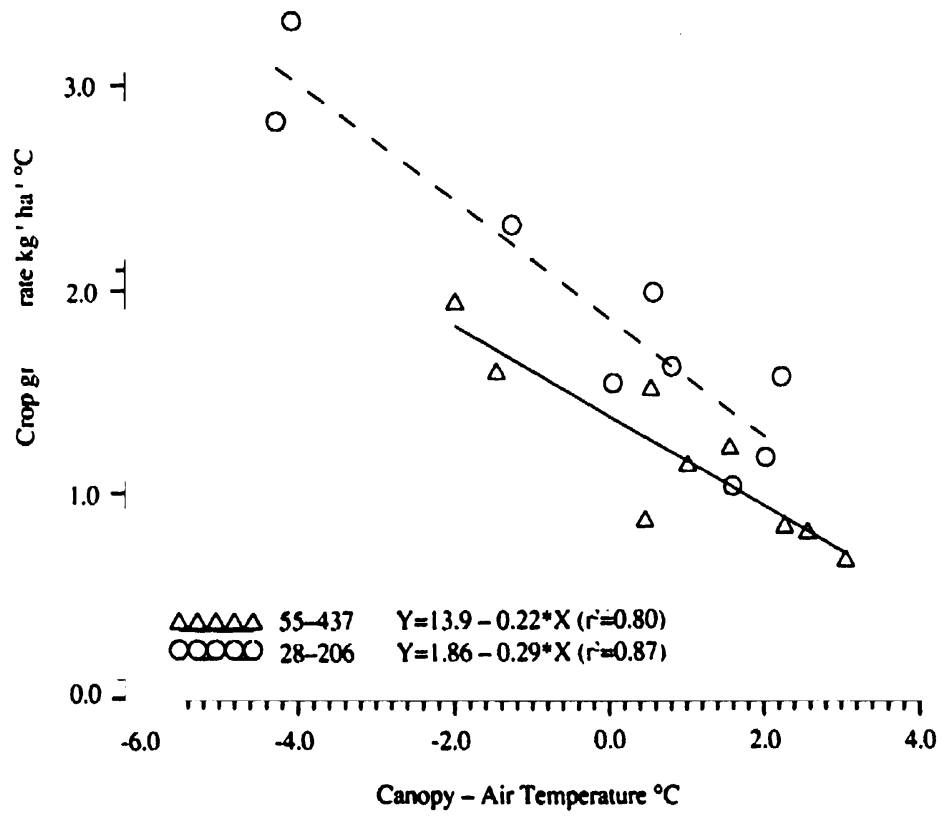

Fig. 2. Crop growth rate $\left(\mathrm{kg} \mathrm{ha}^{-1}{ }^{\circ} \mathrm{Cd}\right)$ of contrasting genotypes as related to canopy-air temperature differences. 
Table 3. Stability of partitioning across environments for 35 groundnut genotypes at ICRISAT Sahelian Center, 1989

\begin{tabular}{lrrrrrrc} 
& \multicolumn{7}{c}{ Stability parameters } \\
Genotype & \multicolumn{1}{c}{$\mathrm{a}$} & s.E.(a) & b1 & s.E.(b1) & b2 & s.E.(b2) & R $^{2}$ \\
ICGV 87259 & 0.170 & 0.073 & 0.669 & 0.120 & & & 0.912 \\
ICGV 87260 & -0.226 & 0.128 & 1.117 & 0.209 & & & 0.905 \\
ICGV 87255 & -0.209 & 0.064 & 1.060 & 0.104 & & & 0.972 \\
ICGV 86206 & -0.050 & 0.064 & 1.027 & 0.104 & & & 0.970 \\
ICGV 86599 & 0.001 & 0.061 & 0.711 & 0.100 & & & 0.944 \\
ICGV 86621 & 0.112 & 0.016 & 0.881 & 0.026 & & & 0.997 \\
ICGV 86630 & -0.132 & 0.054 & 0.964 & 0.088 & & & 0.975 \\
ICGV 86644 & 0.056 & 0.090 & 0.695 & 0.147 & & & 0.882 \\
ICGV 86647 & 0.105 & 0.100 & 0.819 & 0.164 & & & 0.893 \\
ICGV 86055 & 0.131 & 0.036 & 1.025 & 0.058 & & & 0.990 \\
ICGV 86056 & 0.173 & 0.052 & 0.858 & 0.085 & & & 0.972 \\
ICGV 86061 & 0.086 & 0.035 & 1.001 & 0.057 & & & 0.990 \\
ICGV 86015 & 0.246 & 0.136 & 0.841 & 0.221 & & & 0.828 \\
ICGV 87354 & -0.225 & 0.079 & 1.161 & 0.129 & & & 0.964 \\
ICGV 86352 & -0.131 & 0.061 & 1.035 & 0.100 & & & 0.973 \\
55-437 & -0.161 & 0.028 & 2.409 & 0.344 & -1.156 & 0.279 & 0.995 \\
TS 32-1 & 0.071 & 0.067 & 1.026 & 0.110 & & & 0.967 \\
ICGV 86973 & -0.131 & 0.100 & 1.023 & 0.163 & & & 0.929 \\
ICGV 86977 & -0.150 & 0.039 & 1.140 & 0.063 & & & 0.991 \\
ICGV-SM 85005 & -0.103 & 0.052 & 1.059 & 0.085 & & & 0.981 \\
ICGV.SM 83708 & -0.225 & 0.051 & 1.248 & 0.083 & & & 0.987 \\
ICGV-SM 85038 & -0.256 & 0.081 & 1.270 & 0.133 & & & 0.968 \\
ICGV-SM 85045 & 0.035 & 0.059 & 1.018 & 0.096 & & & 0.974 \\
ICGV 86047 & 0.171 & 0.029 & 0.950 & 0.047 & & & 0.993 \\
ICGV 86063 & 0.087 & 0.048 & 1.021 & 0.079 & & & 0.982 \\
ICGV 86072 & 0.006 & 0.075 & 1.084 & 0.122 & & & 0.963 \\
ICGV 87123 & -0.103 & 0.022 & 1.797 & 0.262 & -0.061 & 0.213 & 0.997 \\
ICGV 87141 & -0.096 & 0.050 & 1.236 & 0.082 & & & 0.987 \\
ICGV 86028 & -0.250 & 0.102 & 1.270 & 0.167 & & & 0.951 \\
ICG 1697 & 0.071 & 0.060 & 0.683 & 0.099 & & & 0.941 \\
796 & 0.135 & 0.034 & 1.862 & 0.408 & -0.978 & 0.331 & 0.988 \\
J11 & -0.284 & 0.036 & 2.660 & 0.431 & -1.307 & 0.349 & 0.914 \\
JL 24 & -0.196 & 0.083 & 1.210 & 0.135 & & & 0.964 \\
28-206 & 0.033 & 0.092 & 0.006 & 1.121 & 0.984 & 0.910 & 0.971 \\
WB-9 & -0.047 & 0.059 & 2.189 & 0.713 & -1.059 & 0.578 & 0.978 \\
& & & & & & &
\end{tabular}

\section{Discussion}

In this series of trials we evaluated genotypes in a number of environments that differed substantially in both the availability of water for plant growth, and in the demand for this water as determined by the temperature, relative humidity and radiation levels. Each environment resulted in different pod and biomass (averaged across genotypes) yields (Table 1), and the stability analysis indicated strong $G \times E$ interactions, particularly so for partitioning.

Table 1 shows that the highest pod yields were achieved in the normal rainy season, providing that water was available throughout the crop's life cycle. However, this environment was not the best for total productivity $\left(E_{1}\right.$ was), probably reflecting the fact that the temperatures (de Beer, 1963) and humidity (Lee et al., 1972) in the rainy season are more suitable for reproductive processes, and that growth processes are more tolerant of 


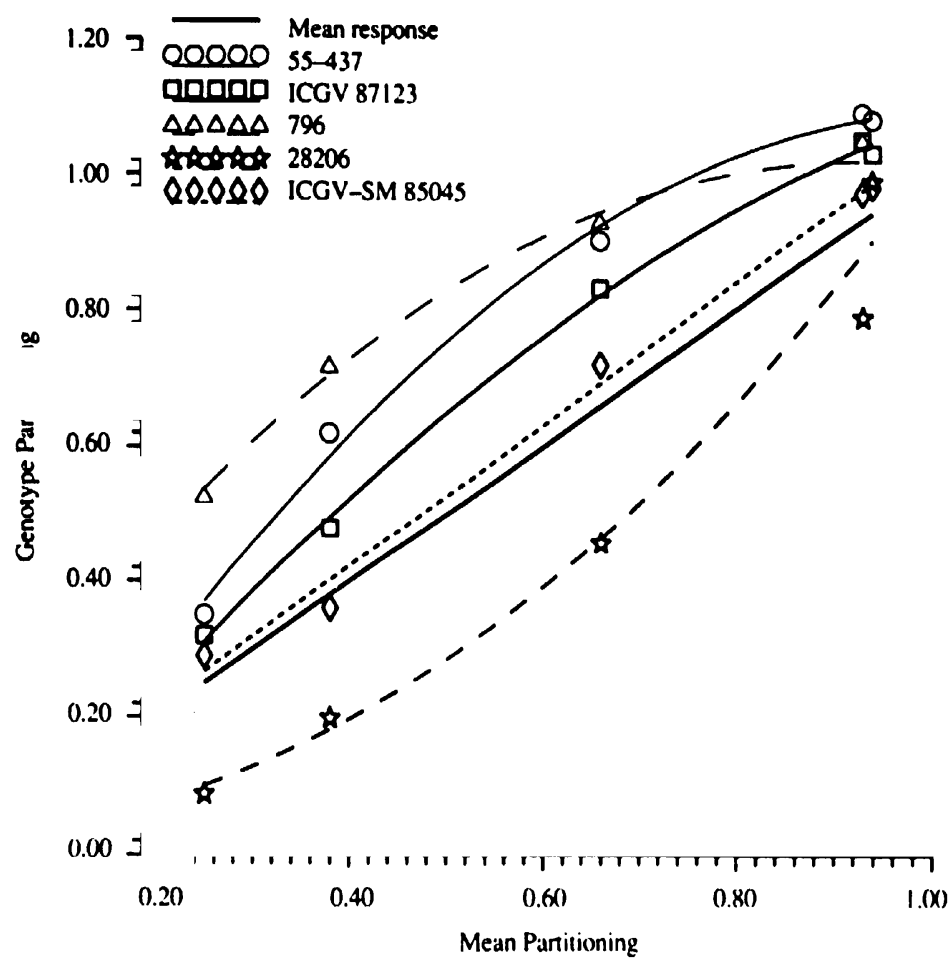

Fig. 3. Partitioning of example varieties relative to the mean of 35 genctypes in five environments.

environmental conditions than are the reproductive processes. The comparison between these environments shows the importance of partitioning to the determination of pod yield (Duncan et al., 1978).

Between the $E_{1}$ and $E_{4}$ environments the differences in $C$ must be attributed mainly to differences in canopy development between environments and genotypes; and the associated differences in energy interception on a crop basis.

The relationship between C and CATD is to be expected across environments since these were dominated by differences in water supply and in this environment where the air is dry, evaporative cooling is a significant component of the energy balance of leaves (Monteith \& Unsworth, 1990). The cooler leaves of genotypes, like 28-206, within environments $E_{1}-E_{3}$ is suggestive of larger root systems, a possibility created by the longer maturity and lower partitioning which probably allows for larger root systems to develop.

Where water is a limitation to growth, $\mathrm{C}$ is the outcome of the crop's ability to capture and transpire water, and the ratio of water use to carbon assimilated (Passioura, 1977). The different total dry mass of varieties within restricted water supply environments $\left(E_{2}\right.$ and $E_{3}$ ) indicates differences in either water capture or transpiration:assimilation ratio. It appears that differences in water capture were a major factor in these differences because of the differences in CATD.

Across this set of environments where water supplied was the dominant basis for differences in C, the stability parameters (a and b; Finlay \& Wilkinson, 1963) may have physiological significance. A positive intercept term for the regression would indicate an above average growth rate in the driest environments and suggests drought resistance/ adaptation advantages. However, since the "a" term was inversely related to the slope (" $b$ " 
term) any selection for these attributes seems likely to have to be offset against poorer performance in the better environments. While we do not have data on the distribution of growth between root and shoot, the inverse relationship is suggestive of differences between genotypes in the emphasis that they place on root or shoot growth (J. Watterrott \& J. H. Williams, unpublished data).

Partitioning differences between genotypes and environments reflect the ability of crops to initiate enough fruit to utilise the carbon assimilates available. The extent of change in the partitioning parameter may be expected to be influenced by the timing of drought. Drought during the pod filling stage may be expected to maximise partitioning since the established fruit generally have priority for the available assimilates in the event of stress (Williams, Wilson \& Bate, 1976), while stress during reproductive establishment generally decreases the fruit set (Harris, et al., 1988) and may therefore be expected to decrease the partitioning. The prevailing temperatures during trial 1 were above $33^{\circ} \mathrm{C}$, a temperature that has been shown to reduce flower development (Fortanier, 1957; de Beer, 1963). In $E_{1}$ the failure to produce pods to utilise the available growth, (despite the high crop growth rates in this environment since the water requirements were met) suggests that temperature and/or humidity were major limiting environmental factors.

The stability of partitioning of genotypes across these environments was very strongly influenced by the genotypes' responses in $E_{1}$ and $E_{2}$. In these environments the genotypes with known tolerances to drought (55-437 796 and ICGV 87123) maintained above average partitioning, while other lines were much less than average (e.g. 28-206). But the high p of these drought tolerant and "Sahel adapted" varieties in the $E_{1}$ environment also suggests that temperature and/or low humidity tolerances are a major component of the "drought tolerances", rather than differences in their response to water supply. Research to provide a better understanding of the basis for the partitioning advantages of "drought resistant" genotypes is likely to improve the ability to identify these types. Considering the association of drought with higher plant and atmospheric temperatures, tolerance of reproductive processes to high temperatures is a desirable attribute for drought prone environments.

This analysis suggest that (for the Sahelian Zone) more variation exists for attributes that maintain partitioning in the face of drought/heat stress than does variation for attributes which increase crop growth rate. For breeding purposes selection for high partitioning in a single environment $\left(E_{1}\right)$ would seem likely to be effective in identifying for further evaluation genotypes with many of the desired attributes.

\section{Acknowledgements}

We would like to thank Mr G. Fatondji, Research Assistant in the Groundnut Improvement Programme for his assistance in the conduct and analysis of this work.

\section{References}

Blum, A. \& Ebercon, A. (1981). Cell membrane stability as a measure of drought and heat tolerance in wheat. Crop Science 17, 149-153.

Blum, A. \& Sullivan, C. Y. (1986). The comparative drought resistances of landraces of sorghum and millet from dry and humid regions. Annals of Botany 57, 835-846.

Chaudhuri, U. N., Deaton; M. L., Kanemasu, E. T., Wall, G. W., Marcarian, V. \& Dobrez, A. K. (1986). A procedure to select drought-tolerant sorghum and millet genotypes, using canopy temperature and vapour pressure deficit. Agronomy Journal 78, 490-494. 
de Beer, J. F. (1963). The influences of temperature on Arachis hypogaea with special reference to its pollen viability. Ph.D. Thesis, State Agricultural University, Wageningen, The Netherlands.

Duncan, W. G., McCloud, D. E., McGraw, R. \& Boote, K. J. (1978). Physiological aspects of peanut yield improvement. Crop Science 18, 1015-1020.

Finlay, K. W. \& Wilkinson, G. N. (1963). The Analysis of Adaptation in a Plant-Breeding Programme. Australian Journal of Agricultural Research 14, 742-754.

Flohr, M-L., Williams, J. H. \& Lenz, F. (1990). The effect of photoperiod on the reproductive development of a photoperiod sensitive groundnut (Arachis hypogaea L.) Cv. Nc ac 17090. Experimental Agriculture 26, 397-406.

Fortanier, E. J. (1957). De beinuloeding van de bloej by Arachis hypogaea L. Ph.D. Thesis, State Agricultural University, Wageningen, The Netherlands.

Gautreau, J. \& de Pins, O. (1980). Groundnut production and research in Senegal. In Proceedings of the International Workshop on Groundnut, 13-17 October, 1980, pp. 274-281. Patancheru, A.P. India: ICRISAT (International Crops Research Institute for the Semi-arid Tropics).

Harris, D., Matthews, R. B., Nageswara Rao, R. C. \& Williams, J. H. (1988). The physiological basis for yield differences between four genotypes of groundnut (Arachis hypogaea L.) in response to drought. 3. Developmental processes. Experimental Agriculture 24, 215-226.

Lee, T. A., Ketring, D. L. \& Powell, R. D. (1972). Flowering and growth responses of peanut plants at two levels of relative humidity. Plant Physiology 48, 190.

Mohamed, H. A., Clark, J. A. \& Ong, C. K. (1988). Genotype differences in the temperature responses of tropical crops. Journal of Experimental Botany 39, 1121-1128.

Monteith, J. L. \& Unsworth, M. H. (1990). Principles of Environmental Physics. Second Edition. London, New York, Melbourne and Auckland: Edward Arnold.

Passioura, J. B. (1977). Grain yield, harvest index and water use of wheat. Journal of Australian Institute of Agricultural Science 43, 117-120.

Rajendrudu, G. \& Williams, J. H. (1987). Effect of gypsum and drought on pod initiation and crop yield in early maturing groundnut (Arachis hypogaea) genotypes. Experimental Agriculture 23, 259271.

Williams, J. H., Wilson, J. H. H. \& Bate, G. C. (1976). The influence of defoliation and pod removal on growth and dry matter distribution in groundnuts (Arachis hypogaea L. cv. Makulu Red.). Rhodesian Journal of Agricultural Research 14, 111-117.

(Received 11 September 1990) 